\title{
Pyloric Stenosis
}

National Cancer Institute

\section{Source}

National Cancer Institute. Pyloric Stenosis. NCI Thesaurus. Code C34966.

Narrowing of the pyloric lumen caused either by hypertrophy of the surrounding muscles or tissue scarring due to a chronic peptic ulcer. 